\title{
The CMS Innovation Center: Delivering on the Promise of Payment and Delivery Reform
}

\author{
Sachin H. Jain, MD, MBA ${ }^{1,2,3}$ and William H. Shrank, MD, MSHS ${ }^{4}$ \\ ${ }^{1}$ Harvard Medical School, Boston, MA, USA; ${ }^{2}$ Boston VA Medical Center, Boston, MA, USA; ${ }^{3}$ Merck and Co, Whitehouse Station, NJ, USA; ${ }^{4}$ CVS \\ CareMark, Inc, Woonsocket, RI, USA.
}

J Gen Intern Med 29(9):1221-3

DOI: $10.1007 / \mathrm{s} 11606-014-2844-7$

(c) Society of General Internal Medicine 2014

$\mathrm{W}$ ith wide recognition of the unsustainability of US health care costs, the need to identify significant sources of savings has never been greater. One important historical source of ingenuity in this domain has been the research and demonstration functions of the Health Care Financing Administration (HCFA). From the late 1970s through the 1990s, HCFA conducted a wide-range of demonstrations that included the development of diagnosis-related groups and testing their use in paying for inpatient hospital care. It also developed demonstrations of prospective payment for skilled-nursing facilities. These changes, developed at a cost of $\$ 28$ million, resulted in $\$ 64$ billion in savings in the 10 years after they were more broadly implemented.

In 2001, HCFA was renamed the Center for Medicare and Medicaid Services (CMS), and its research groups continued to produce critical innovations. They developed the foundations for the home health care prospective payment system (PPS), Medicare Advantage and Part D program risk adjustment methodologies; several key bundled payments initiatives; and the Physician Group Practice (PGP) demonstration - the precursor to Accountable Care Organizations (ACOs)-among others.

While CMS research programs generated many important insights, they faced two recurring constraints. First, funding streams from Congress were inconsistent. Between 2001 and 2009, funds allocated for research and demonstrations fell steadily from $\$ 140$ million to $\$ 25$ million in real dollars, severely limiting CMS's capacity. Second, Congressional action was required to execute upon lessons learned from demonstrations. As a result, there were often delays between the conclusion of demonstrations and policy and program changes to the Medicare program; there was no path ensuring that successful demonstrations would translate into new payment or delivery models.

Recognizing these obstacles, Congress authorized the creation of a new Center for Medicare and Medicaid

Published online April 1, 2014
Innovation (CMMI). The Affordable Care Act (ACA) appropriates $\$ 10$ billion to the Center between FY2011 and 2019 to test new models of payment and delivery. More importantly, it authorizes the Secretary of Health and Human Services to bring to national scale via rulemaking any demonstration that improves quality while keeping costs constant, decreases costs while maintaining quality or, in the best case, reduces costs while improving quality. The Congressional Budget Office has estimated that the Center will lead to $\$ 1.3$ billion in net savings - $\$ 11.3$ billion in total savings-over its first 10 years of operation. To capitalize on this opportunity and fulfill these ambitions, CMMI must fulfill three imperatives.

The first imperative will be to develop a portfolio of demonstration models that is sufficiently broad. The initial portfolio of Innovation Center programs addresses quality and efficiency improvements at four levels: better care for particular diseases and populations; enhanced system integration; prevention efforts for improved community and population health; and state innovation models. The test of the effectiveness of this framework will lie in whether it affects patterns of care and outcomes for the most significant sources of morbidity and mortality for Medicare and Medicaid beneficiaries; and, also, whether it rapidly introduces changes in the Medicare and Medicaid programs that make them more sustainable.

To start along this path, the Innovation Center has developed programs (see Table 1) to enhance coordination of care for patients who are eligible for both Medicare and Medicaid (so-called "dual eligibles"), test interventions to achieve goals in patient safety and decreasing readmissions, and test new, advanced models of Accountable Care Organizations (the Pioneer ACO Program), which complement the ACOs that are created by the Medicare Shared Savings program. In addition, the Innovation Center has launched the comprehensive primary care initiative, a multipayer effort to redesign primary care; bundled payment models for acute care, acute and post-acute episodes, and post acute care episodes; and a State Innovation model to work collaboratively with state governments to promote payment model and care redesign. Lastly, the Innovation Center has launched a host of models focused on priority issues and populations such as maternal health and cardiovascular prevention. Many demonstration projects 
Table 1. Models Being Tested by the Innovation Center

\begin{tabular}{|c|c|}
\hline Initiative & Test \\
\hline Comprehensive Primary Care Initiative & $\begin{array}{l}\text { Public-private partnership to enhance primary care services, including } \\
\text { 24-h access, care plans, and care coordination }\end{array}$ \\
\hline Federally Qualified Health Center (FQHC) & Care coordination payments to FQHCs in support of team-led care, \\
\hline Pioneer ACO Model & $\begin{array}{l}\text { Experienced provider organizations taking on financial risk for improving } \\
\text { quality and lowering costs for their aligned Medicare patients }\end{array}$ \\
\hline Advance Payment ACO Model & $\begin{array}{l}\text { Prepayment of expected shared savings to support ACO infrastructure and } \\
\text { care coordination }\end{array}$ \\
\hline Bundled Payment for Care Improvement & $\begin{array}{l}\text { Four different models of episodic payments around inpatient hospitalization } \\
\text { to incentivize care redesign: } \\
\text { Model 1: Retrospective Acute Care Episode } \\
\text { Model 2: Retrospective Acute Care Episode \& Post Acute } \\
\text { Model 3: Retrospective Post Acute Care } \\
\text { Model 4: Prospective Acute Care }\end{array}$ \\
\hline The Partnership for Patients & $\begin{array}{l}\text { Partnership for Patients: Efficacy of hospital engagement networks (other interventions) } \\
\text { in reducing HACs/Readmissions by } 20 \text { and } 40 \% \text {, respectively. } \\
\text { Community-Based Care Transitions Program (a part of the Partnership for Patients) } \\
\text { reduces readmissions by improving transitions of high-risk Medicare beneficiaries } \\
\text { from the inpatient hospital setting to home or other care settings* }\end{array}$ \\
\hline Health Care Innovation Awards & $\begin{array}{l}\text { A broad range of innovations with a focus on developing the workforce for } \\
\text { new care models }\end{array}$ \\
\hline $\begin{array}{l}\text { State Demonstrations to Integrate Care for } \\
\text { Medicare-Medicaid Enrollees }\end{array}$ & $\begin{array}{l}\text { Support for States to design new approaches to integrated care models for } \\
\text { Medicare-Medicaid enrollees }\end{array}$ \\
\hline $\begin{array}{l}\text { Financial Alignment Initiative to Support State Efforts } \\
\text { to Integrate Care for Medicare-Medicaid Enrollees }\end{array}$ & $\begin{array}{l}\text { Opportunity for States to test two new models to integrate care and better align } \\
\text { payment systems for Medicare-Medicaid enrollees }\end{array}$ \\
\hline Initiative to Reduce Avoidable Hospitalizations & Initiative to improve quality of care and reduce avoidable hospitalizations among \\
\hline Among Nursing Facility Residents & $\begin{array}{l}\text { long-stay nursing facility residents by partnering with independent organizations } \\
\text { with nursing facilities, to test enhanced on-site services and supports to reduce } \\
\text { inpatient hospitalizations }\end{array}$ \\
\hline Strong Start for Mothers and Newborns & $\begin{array}{l}\text { Strategy I: Testing the effectiveness of shared learning and diffusion activities } \\
\text { to reduce the rate of early elective deliveries among pregnant women } \\
\text { Strategy II: Testing and evaluating a new model of enhanced prenatal care to reduce } \\
\text { preterm births (less than } 37 \text { weeks) in women covered by Medicaid }\end{array}$ \\
\hline State Innovation Models & $\begin{array}{l}\text { Financial, technical, and other support to states that are either prepared to test, } \\
\text { or are committed to designing and testing new payment and service delivery } \\
\text { models that have the potential to reduce health care costs in Medicare, } \\
\text { Medicaid, and CHIP }\end{array}$ \\
\hline
\end{tabular}

*Source: Centers for Medicare and Medicaid Services

are unlikely, in and of themselves, to effect the broad changes that they aim to achieve; instead, it will be the widespread implementation of effective strategies that achieves these goals.

A second key imperative will be to use both formative and summative approaches of evaluation in such a way as to accelerate wide-scale change. It is crucial for the Innovation Center to master both the traditional methods of evaluation that have been the hallmark of CMS to make evidence-based policy decisions, and also different approaches to rapid iterative learning and development, to help providers rapidly incorporate new information about success and failure into their products, services, and processes. Early results from many Pioneer ACOs demonstrate sound quality results and lower than expected costs. The Partnership for Patients program is also showing early positive results in the form of quantifiably reduced patient harm and readmissions in participating hospitals. Learning from the early results of these programs and their implementation should lead to iterations and changes in the regulations guiding them.

A third key imperative will be to establish a threshold for the effectiveness of a new payment or delivery model. Designating a new model of care or payment as "effective" based on demonstration will no doubt be subject to ongoing debate, since demonstration results will surely be context dependent and nuanced. If a new ACO model, for example, is appropriately tested in several urban areas, can its results be reasonably extrapolated to other geographic locales or provider organizations? In how many settings must a new model of primary care be tested before it is deemed effective enough to bring to national scale? How will the Innovation Center consider models that are effective in some environments and not others? The ultimate arbiter of the effectiveness of any models will be the independent CMS Office of the Actuary. Since the Innovation Center's creation, discussions have been ongoing between the Innovation Center and the Office of the Actuary as to how the evidence threshold for spread will be determined - but no clear answer has yet emerged.

CMS has a rich history of testing new models of payment and delivery, the results of which have yielded major savings. With rising health care costs and a growing population of Medicare and Medicaid beneficiaries, the need for identifying and bringing to scale health care innovations that both improve quality and reduce costs has never been greater. Absent successful innovation, we may be forced to rely on more blunt restrictions 
that neither patients nor those who care for them will welcome. Building on its history of demonstrations, the CMS Innovation Center has the potential to be a key driver in the modernization of the Medicare and Medicaid programs and in the improvement of the American health care system as a whole. Only time will tell whether it fully achieves this potential, but it is off to a propitious start.
Disclaimer: The authors were members of the founding leadership team of the Center for Medicare and Medicaid Innovation. The opinions expressed here are solely their own, not any official views of the US government or any of the organizations with which they are currently affiliated.

Corresponding Author: Sachin H. Jain, MD, MBA; Harvard Medical School, Boston, MA, USA (e-mail: shjain@post.harvard.edu). 